\title{
VE-822 mediated inhibition of ATR signaling sensitizes chondrosarcoma to cisplatin via reversion of the DNA damage response
}

This article was published in the following Dove Press journal: OncoTargets and Therapy

\author{
Xiao Liang' \\ Qiya Yang ${ }^{2}$ \\ Wanchun Wang' \\ Tang Liu' \\ Jinyue $\mathrm{Hu}^{3}$
}

'Department of Orthopaedics, The Second Xiangya Hospital, Central South University, Changsha, Hunan 4I00II, People's Republic of China; ${ }^{2}$ Chengnan Academy, Hunan First Normal University, Changsha, Hunan 410002, People's Republic of China; ${ }^{3}$ Medical Research Center, Changsha Central Hospital, Changsha, Hunan 4I0004, People's Republic of China
Correspondence: Wanchun Wang Department of Orthopaedics, The Second Xiangya Hospital, Central South University, Changsha, Hunan 4I00II, People's Republic of China

Fax +8673185295128

Email wanchun.wang@csu.edu.cn

Jinyue $\mathrm{Hu}$

Medical Research Center, Changsha Central Hospital, Changsha, Hunan 410004, People's Republic of China

Fax +8673185668157

Email jinyueh@yahoo.com
Introduction: Cisplatin has been reported to elicit the DNA damage response (DDR) via activation of the ATR-Chk1 pathway, which in turn contributes to the induction of cisplatin resistance. Inhibition of ATR-Chk1 signaling reverses cisplatin resistance in some cancers. However, the influence of inhibiting ATR-Chk1 signaling on cisplatin resistance in chondrosarcoma cancer has not been reported.

Materials and methods: We compared the expression levels of ATR kinases in human nasopharyngeal carcinoma, choriocarcinoma and chondrosarcoma cell lines. We inhibited ATR kinase function with VE-822, a selective ATR inhibitor, and suppressed ATR kinase expression with shRNA. Western blotting, the CCK-8 assay, cell cycle distribution assay and apoptosis analysis were used to study the influence of inhibiting ATR-Chk1 signaling on reversing cisplatin resistance in chondrosarcoma cell lines.

Results: We found that chondrosarcoma cells expressed very low basal levels of phosphorylated ATR, but cisplatin treatment induced the activation of ATR-Chk1 signaling in a doseand time-dependent manner, suggesting the induction of DDR. As expected, ATR inhibition with VE-822 reversed cisplatin-induced DDR and enhanced cisplatin-induced activation of $\mathrm{H} 2 \mathrm{AX}$, which is an important marker of DNA damage. Meanwhile, ATR inhibition by RNA interference also reversed DDR and promoted DNA damage. Furthermore, both pharmacological and molecular inhibition of ATR accelerated cisplatin-induced inhibition of cell proliferation and cell death.

Conclusion: Our results suggested that inhibiting ATR activation promoted cisplatininduced cell death via reversion of DDR, and VE-822 may be a valuable strategy for the prevention of cisplatin resistance in chondrosarcoma.

Keywords: chondrosarcoma, ATR, VE-822, DNA damage response, cell death

\section{Introduction}

Chondrosarcoma $(25.8 \%)$ is the second most frequently diagnosed primary sarcoma of bone following osteosarcoma $(35.1 \%) .{ }^{1}$ The vast majority $(90 \%)$ of these cancers are conventional chondrosarcomas, which are subdivided into the central, peripheral and periosteal subgroups. ${ }^{2}$ The remaining $10 \%$ are rare variants of chondrosarcoma, which include dedifferentiated, clear cell and mesenchymal chondrosarcomas. ${ }^{2}$ The 5 -year survival rate of patients with grade I chondrosarcoma is $83 \%$, whereas patients with grade II or III disease have a combined 5-year survival rate of only $53 \%{ }^{3}$ Due to the limited clinical efficacies of chemotherapy and radiotherapy, broad surgical resection of the tumor is the most efficient and 
commonly used treatment method. However, after surgical treatment, the tumor tends to recur in subsequent years, and the degree of malignancy often increases over time. Furthermore, surgical treatment is not applicable to metastatic or unresectable disease. Therefore, improving the chemosensitivity and radiosensitivity of chondrosarcoma can diversify treatment programs and significantly improve the survival of patients.

Ataxia telangiectasia mutated (ATM) and ATM- and RAD3-related (ATR) kinase are key regulators of the DNA damage response (DDR) signal pathway. ${ }^{4}$ Once DNA damage occurs, the ATR-Chk1 and ATM-Chk2 pathways halt cell cycle progression at the G2/M and G1/S checkpoints, respectively, to allow time for DNA repair. Activation of the ATR-Chk1 pathway initiates cell cycle arrest, DNA repair and stabilization of the replication fork.

VE-822, the improved molecule of VE-821, is a novel ATR inhibitor with high selectivity and specificity to prevent signal transduction of the ATR-Chk1 pathway. ${ }^{5}$ In general, irradiation and chemotherapeutic drugs induce DNA damage, which triggers the activation of the ATRChk1 and ATM-Chk2 pathways and renders the cell cycle halted in the G2 and G1 phases, respectively, to facilitate DNA repair. However, ATR inhibition with VE-822 forces cells with DNA damage in G2 phase to rapidly progress into $M$ phase with DNA repair that is severely incomplete. Cells with damaged DNA fail to divide to the next generation and instead shift toward mitotic catastrophe. ${ }^{6}$ Therefore, VE-822 has a dramatic impact on cells active within the cell cycle, such as cancer cells, leading to a sharp increase in the number of apoptotic cells. However, this treatment is ineffective let alone beneficial for the survival of noncycling cells, such as healthy normal cells. ${ }^{7}$

Some experimental studies have indicated that VE-822 can enhance the sensitivity of several cancer lines to chemotherapy and irradiation. ${ }^{8-10}$ However, VE-822 has never been reported to increase the chemosensitivity or radiosensitivity of chondrosarcoma. Our study systematically elaborated the effectiveness of VE-822 to increase the chemosensitivity of chondrosarcoma cells to cisplatin.

\section{Materials and methods}

\section{Cell culture}

SW1353, and JEG-3 cells were purchased from the American Type Culture Collection (American Type Culture Collection) and cultured in Dulbecco's modified Eagle's medium (DMEM) supplemented with 10\% fetal bovine serum (BI Inc.), 100 units $/ \mathrm{ml}$ penicillin and $100 \mu \mathrm{g} / \mathrm{ml}$ streptomycin (BI Inc.). CS-1 is a human chondrosarcoma cell line, kindly provided by Dr. Zhenfeng Duan (Sarcoma Biology Laboratory, Center for Sarcoma and Connective Tissue Oncology, Massachusetts General Hospital). ${ }^{11} 5-8 \mathrm{~F}$ is a nasopharyngeal carcinoma cell line, ${ }^{12}$ kindly provided by Dr. H.M. Wang (Cancer Center, Sun Yat-sen University, China). ${ }^{13}$ The use of all these cell lines was approved by the Ethics Committee of Changsha Central Hospital and the Ethics Committee of the Second Xiangya Hospital. All cells were maintained at $37^{\circ} \mathrm{C}$ in a humidified incubator with $5 \% \mathrm{CO}_{2}$. The medium was changed every two or three days.

\section{Cell viability assay}

Cell viability after cisplatin treatment combined with VE822 was determined using CCK-8 reagent purchased from Dojindo (Kumamoto, Japan). In brief, chondrosarcoma cells $\left(1 \times 10^{4}\right.$ per well $)$ were seeded into 96-well plates and cultured overnight at $37^{\circ} \mathrm{C}$ in a humidified incubator. Compared with the control wells, the experimental wells were treated with cisplatin and/or VE-822. All treatments were performed in triplicate. After $24 \mathrm{~h}$ of treatment, $10 \mu \mathrm{l}$ of CCK-8 reagent was added per well (containing $100 \mu \mathrm{l}$ of DMEM) according to the manufacturer's instructions. Following an incubation at $37^{\circ} \mathrm{C}$, the absorbance at $450 \mathrm{~nm}$ was measured using a microplate reader (ELx800, BioTek Inc., USA).

\section{Western blot assay}

Cells were lysed with prechilled radioimmunoprecipitation (RIPA) buffer containing phenylmethylsulfonyl fluoride (PMSF) and disrupted 60 times in icy water for $5 \mathrm{~s}$ each with an Ultrasonic Cell Disruption System at intervals of $5 \mathrm{~s}$. After centrifugation at $12,000 \mathrm{rpm} / \mathrm{min}$ at $4^{\circ} \mathrm{C}$ for $10 \mathrm{~min}$, supernatants were collected, and protein concentrations were determined with a BCA protein assay kit (Pierce, Rockford, IL, USA). After the samples were mixed thoroughly with loading buffer, they were heated at $100^{\circ} \mathrm{C}$ for 5 min. Equal amounts of total protein $(20-100 \mu \mathrm{g})$ were separated by SDS-PAGE on a $10 \%$ gel and transferred onto a PVDF membrane. Following blocking by incubation in $3 \%$ dry nonfat milk at room temperature for $1 \mathrm{~h}$, the membrane was incubated with primary antibodies at $4^{\circ} \mathrm{C}$ overnight. Next, the membrane was rinsed three times with PBS-T (containing 0.01\% Tween 20), incubated for $1.5 \mathrm{~h}$ with secondary antibodies conjugated to HRP and rinsed three times with PBS-T. The protein bands were detected 
with SuperSignal chemiluminescent substrate-stable peroxide solution (Pierce Rockford, IL, USA), and reactions in the protein bands were developed on BIOMAX-MR film (Eastman Kodak Co., Rochester, NY, USA).

\section{Apoptosis analysis}

Cells were harvested and washed twice with PBS and subsequently suspended in $200 \mu \mathrm{l}$ of annexin V binding buffer. After the suspension was incubated with Annexin V-FITC in the dark for $15 \mathrm{~min}$ at $4^{\circ} \mathrm{C}$, propidium iodide (PI) was added to the samples and incubated in the dark for $5 \mathrm{~min}$ at $4^{\circ} \mathrm{C}$. The samples were analyzed on a BD Accuri C6 using FACSuite analysis software (BD Bioscience).

\section{ATR knockdown in SWI 353 cells}

Small hairpin (sh)-RNA targeting ATR was integrated into the pLent-U6-GFP-Puro vector. The sequence targeting ATR was as follows: 5'-GCCAAAGTATTTCTAGCC TATCTTCAAGAGAGATAGGCTAGAAATACTTTGGCTTTTTT-3' ${ }^{14}$ Vectors with or without the shRNA targeting ATR were transfected into SW1353 cells using Lipofectamine 3000 (Invitrogen Life Technologies) according to the manufacturer's protocols. Subsequently, monoclonal cells were selected using complete medium supplemented with $1 \mu \mathrm{g} / \mathrm{ml}$ puromycin.

\section{Reverse transcription-polymerase chain reaction (RT-PCR)}

Total RNA was extracted from treated cells using TRIzol reagent (Invitrogen) according to the manufacturer's protocol. For the detection of the mRNA levels, complementary DNA primed by oligo-dT was synthesized with a RevertAid First Strand cDNA Synthesis Kit (Thermo Fisher Scientific, Pittsburgh, PA, USA). Subsequently, PCR was performed for 20-30 cycles under the following cycling conditions: denaturation at $94^{\circ} \mathrm{C}$ for $30 \mathrm{~s}$, annealing at $60^{\circ} \mathrm{C}$ for $30 \mathrm{~s}$, and extension at $68^{\circ} \mathrm{C}$ for $40 \mathrm{~s}$. PCR products were separated on a $1 \%$ agarose gel and then stained with GelRed. The following primers were used:

ATR-forward: 5'-TCCCTTGAATACAGTGGCCTA-3', and ATR-reverse: 5'-TCCTTGAAAGTACGGCAGTTC3'; CHK1-forward: 5'-ATATGAAGCGTGCCGTAGACT3', and CHK1-reverse: 5-TGCCTATGTCTGGCTCTATTC TG-3'; and GAPDH-forward: 5'-AATCCCATCACCATC TTCCA-3', and GAPDH-reverse: 5-CCTGCTTCACCAC CTTCTTG-3'.

\section{Quantitative real-time RT-PCR (qRT-PCR)}

cDNA was synthesized as described previously. Real-time PCR amplification was performed with specific primers on a Roche LightCycler 96 Sequence Detection System. The reactions were prepared using SYBR Green reaction mix from Roche. Using the $2-\Delta \Delta \mathrm{Ct}$ method, the expression levels of the relative mRNAs were normalized to those of GAPDH. The primers used for RT-PCR were used in these experiments.

\section{PI staining of dead cells}

SW1353 cells and the above mentioned monoclonal cells transfected with plasmids with or without ATR shRNA were treated with $10 \mu \mathrm{M}$ cisplatin for $48 \mathrm{~h}$. Then, $1 \mu \mathrm{g} / \mathrm{ml}$ PI was directly added into the control and treated wells, and the cells were incubated at room temperature for $30 \mathrm{~min}$. The bright field and fluorescence images in the same field were captured with fluorescence microscopy (Leica).

\section{Cell cycle analysis}

Cells treated with VE-822 and/or cisplatin were collected and rinsed once with PBS. Then, they were fixed with $70 \%$ ethanol at $4{ }^{\circ} \mathrm{C}$ overnight and rinsed once with PBS. After the cells were suspended with $1 \mathrm{ml}$ PBS per tube, $50 \mu \mathrm{g} / \mathrm{ml}$ RNase was added. Next, $5 \mu \mathrm{g} / \mathrm{ml}$ PI was incubated with the samples in the dark for $30 \mathrm{~min}$ at room temperature, after which the cell cycle distribution was analyzed on a BD Accuri C6 using FACSuite analysis software (BD Bioscience). The percentage of cells in the different phases of the cell cycle was counted and compared. The experiments were repeated in triplicate.

\section{Statistical analysis}

All experiments were repeated three times independently. The results are shown as the mean \pm SD (standard deviation). Either Student's $t$-test or one-way ANOVA was used to analyze the data with SPSS software. $P$-values $<0.05$ were considered to be statistically significant.

\section{Results}

\section{The treatment of chondrosarcoma cells with cisplatin induces the DNA damage response}

It is well known that the clinical effects of cisplatin treatment are relatively ideal for nasopharyngeal carcinoma and endometrial carcinoma compared with chondrosarcoma. We measured the basal levels of phosphorylated ATR kinase in SW1353, CS-1, 5-8F, and JEG-3 cells. 
The results showed that the chondrosarcoma CS-1 cell line and SW1353 cells expressed very low levels of phosphorylated ATR at baseline. As experimental controls, 5-8F and JEG-3 expressed moderate levels of phosphorylated ATR (Figure 1A). Then, we focused on SW1353 and CS-1 cells to investigate the impact of cisplatin on the levels of activated ATR and Chk1, which are two important markers of the DNA damage response (DRR). The phosphorylated ATR kinases in both chondrosarcoma cell lines were significantly upregulated by cisplatin treatment in a dose- and time-dependent manner (Figure 1B and C).
Cisplatin treatment also induced the activation of Chk1, which is a downstream molecule of ATR, in both SW1353 and CS-1 cells in a dose- and time-dependent manner (Figure $1 \mathrm{~B}$ and $\mathrm{C}$ ). These results suggest that cisplatin elicits the DDR in chondrosarcoma.

\section{Inhibition of ATR promotes cisplatin- induced DNA damage}

DNA damage is a key driver of the therapeutic mechanism of chemotherapy of cancers. The ATR-Chk1 pathway can

A

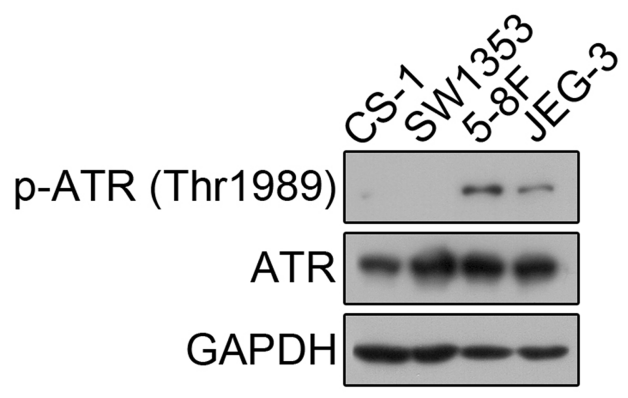

B

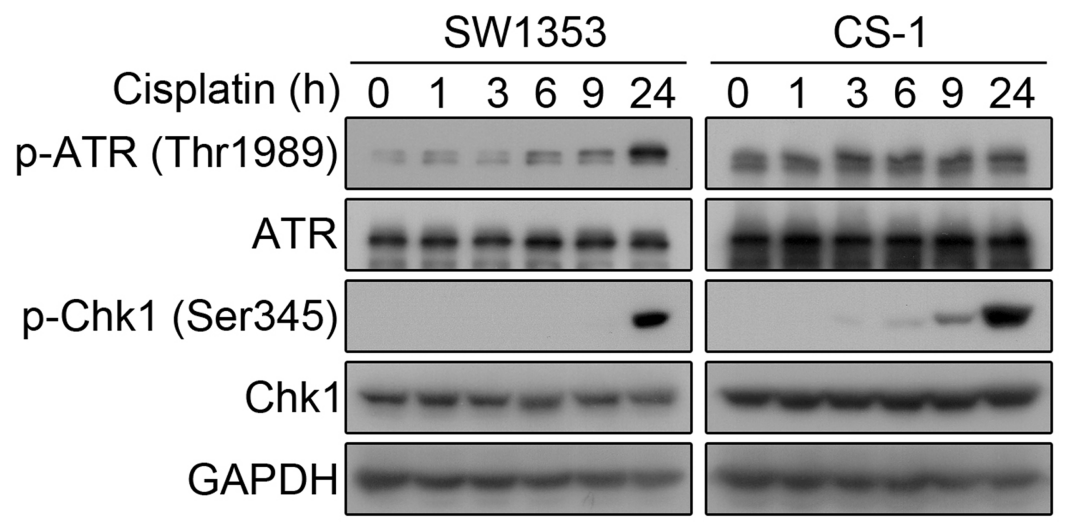

C

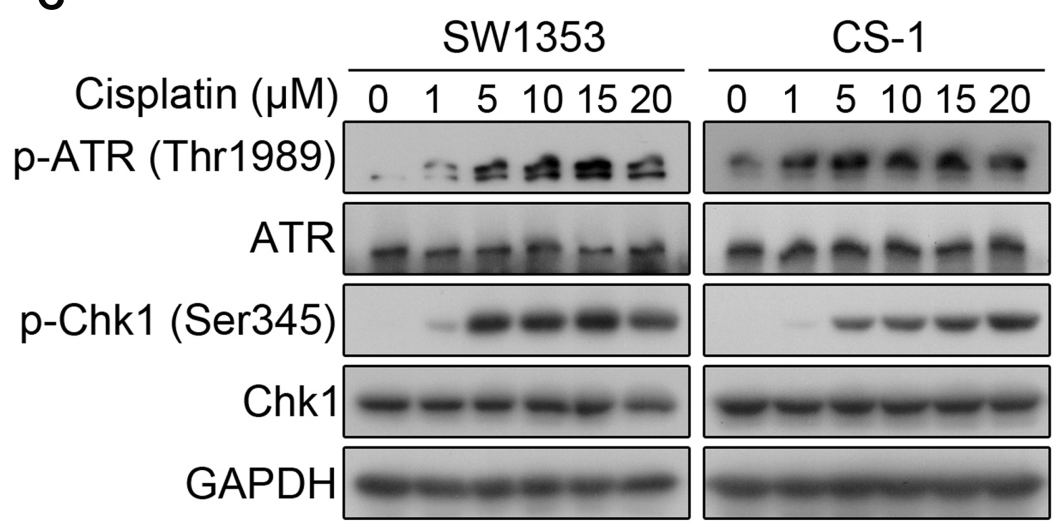

Figure I Cisplatin activates the ATR-Chkl pathway in chondrosarcoma cells. (A) Western blot analysis of the total and phosphorylated levels of basal ATR and ChkI in untreated CS-I, SWI353, 5-8F, and JEG-3 cells. GAPDH protein levels were measured as loading controls. (B) Western blot analysis of the levels of total and phosphorylated ATR and ChkI in CS-I and SWI353 cells treated with $10 \mu \mathrm{M}$ cisplatin for the indicated time periods. (C) Western blot analysis of the levels of total and phosphorylated ATR and ChkI in CS-I and SWI353 cells treated with the indicated concentrations of cisplatin for $24 \mathrm{~h}$. 
be activated by DNA damage and is essential for the survival of many cancer cells in response to multiple anticancer drugs. ${ }^{15}$ Therefore, ATR-Chk1 activation contributes to the induction of drug resistance. ${ }^{16}$ To determine the roles of the ATR-Chk1 pathway in the induction of cisplatin resistance in chondrosarcoma, we tested the effect of the inhibition of ATR on DNA damage induced by cisplatin. We found that cisplatin activated the ATRChk1 pathway in both SW1353 and CS-1 chondrosarcoma cells (Figure 2A and B). Pharmacological inhibition of ATR with VE-822 dose dependently reversed the activation of ATR-Chk1 signaling induced by cisplatin (Figure 2A and B). Cisplatin had little effect on the activation of $\mathrm{H} 2 \mathrm{AX}$, suggesting that cisplatin alone induced a limited amount of DNA damage (Figure 2C and D). However, VE-822 significantly upregulated the activation of H2AX in a dose-dependent manner in both SW1353 and CS-1 cells (Figure 2C and D), suggesting increased DNA damage. Meanwhile, molecular inhibition of ATR via RNA interference downregulated the expression of ATR (Figure 2E), inhibited the activation of the ATRChk1 pathway, and promoted DNA damage induced by cisplatin (Figure $2 \mathrm{~F}$ and $\mathrm{G}$ ). These results suggested that ATR inhibition promoted cisplatin-induced DNA damage and may function to reverse cisplatin resistance in chondrosarcoma.

\section{ATR inhibition sensitizes chondrosarcoma cells to cisplatin-induced inhibition of cell proliferation}

The ATR inhibitor VE-822 has been reported to enhance cisplatin chemosensitivity in esophageal squamous cell carcinoma. ${ }^{9}$ In this study, we detected the effect of VE822 on cell proliferation in chondrosarcoma cells. The results showed that VE-822 alone did not affect the proliferation of either SW1353 or CS-1 cells (Figure 3A). When cells were cotreated with VE-822 and cisplatin, the inhibition of cell proliferation was increased (Figure 3B and C). Meanwhile, we found that ATR downregulation by RNA interference promoted cisplatininduced inhibition of cell proliferation in chondrosarcoma cells (Figure 3D).

\section{ATR inhibition sensitizes chondrosarcoma cells to cisplatin-induced cell death}

Cisplatin has been reported to induce cell cycle arrest at G2/M phase. ${ }^{17}$ To determine the effect of VE-822 on cisplatin-induced cell cycle arrest in chondrosarcoma cells, SW1353 cells were treated with VE-822 alone, cisplatin alone, or VE-822 and cisplatin together. PI staining results showed that VE-822 alone had little effect on the percentage of cells in the G2 and M phases (Figure 4A and $\mathrm{B})$, but cisplatin alone induced significant cell cycle arrest at the G2/M checkpoint (Figure 4A and B). Moreover, VE822 treatment combined with cisplatin significantly decreased the number of cells in G2/M phase but increased the number of cells in G1 phase. These results suggested that cisplatin treatment induced cell cycle arrest at the G2/ $M$ checkpoint to signal DNA repair via activation of the ATR-Chk1 pathway, and the ATR inhibitor VE-822 blocked this mechanism by promoting cell cycle progression from $\mathrm{G} 2 / \mathrm{M}$ to $\mathrm{G} 1$ phase.

Chk1 inhibition has been reported to enhance cisplatin cytotoxicity. ${ }^{18}$ In this study, we tested the effect of ATR inhibition on cisplatin-induced cell death. The results showed that both cisplatin and the ATR inhibitor VE-822 induced very low levels of cell death in SW1353 cells (Figure 4C and D). However, cotreatment of cells with cisplatin and VE822 significantly increased cell death in SW1353 cells (Figure 4C and D). Meanwhile, ATR inhibition by RNA interference significantly promoted cell death induced by cisplatin (Figure 4E and F). Western blot results showed that ATR inhibition upregulated the activation of caspase 3 induced by cisplatin (Figure 4G). These results suggested that ATR inhibition enhanced cisplatin cytotoxicity in chondrosarcoma cells.

\section{Discussion}

In this study, we found that cisplatin treatment of chondrosarcoma cells induced the activation of the ATR-Chk1 pathway, suggesting the induction of the DDR, which may contribute to cisplatin resistance in chondrosarcoma. The ATR inhibitor VE-822 and ATR shRNA reversed cisplatin-induced DDR and promoted DNA damage. Meanwhile, ATR inhibition increased the inhibition of the proliferation of chondrosarcoma cells induced by cisplatin and upregulated cisplatin-induced cell death, suggesting that inhibiting ATR may be a strategy for enhancing the chemosensitivity of chondrosarcoma treated with cisplatin.

Cisplatin was first approved for the treatment of testicular cancer and remains one of the most effective antitumor agents in a wide variety of solid tumors, such as head and neck, lung, bladder, ovarian, and cervical neoplasms. ${ }^{19}$ Although surgical resection is the first treatment option for 

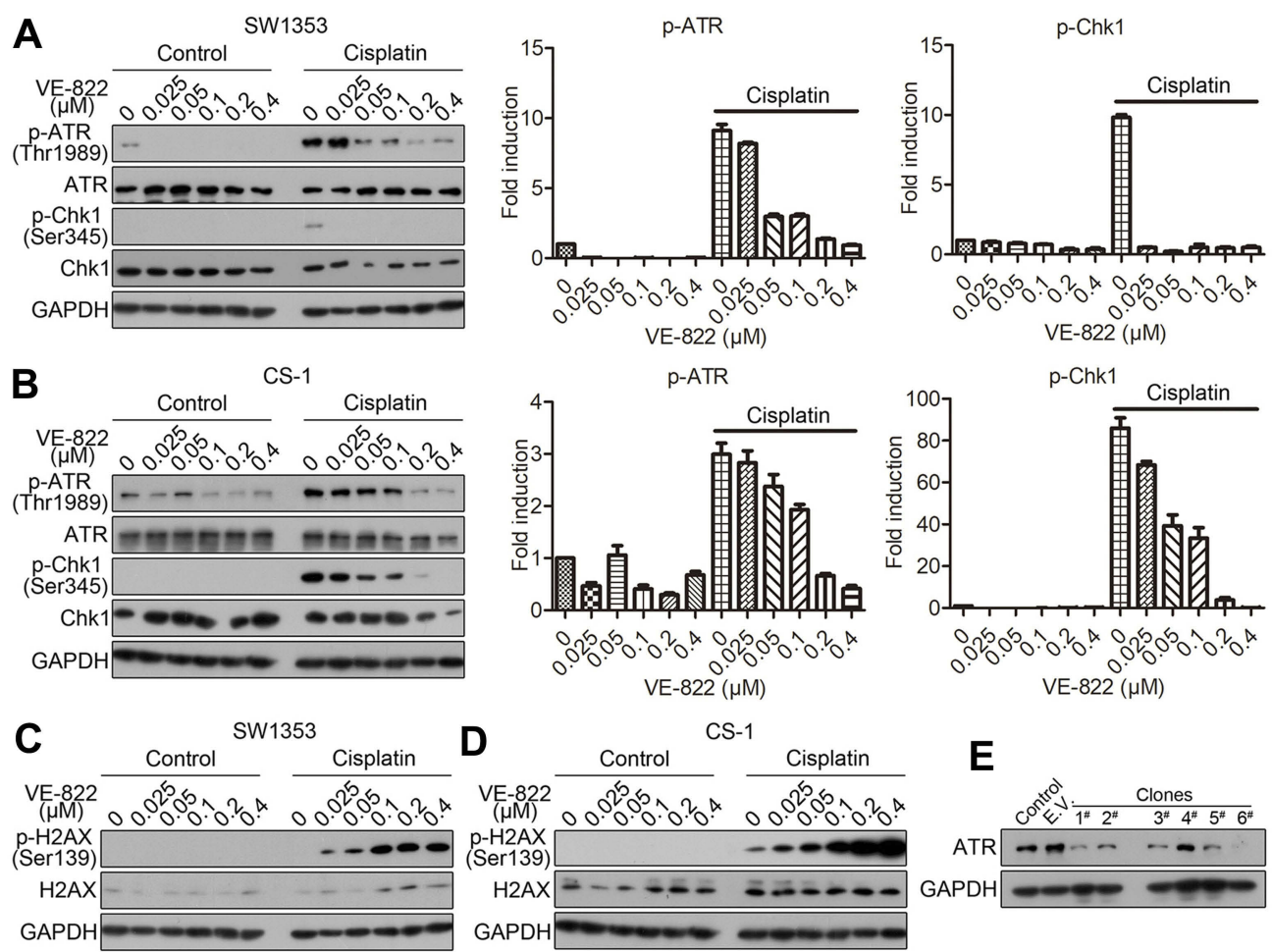

E
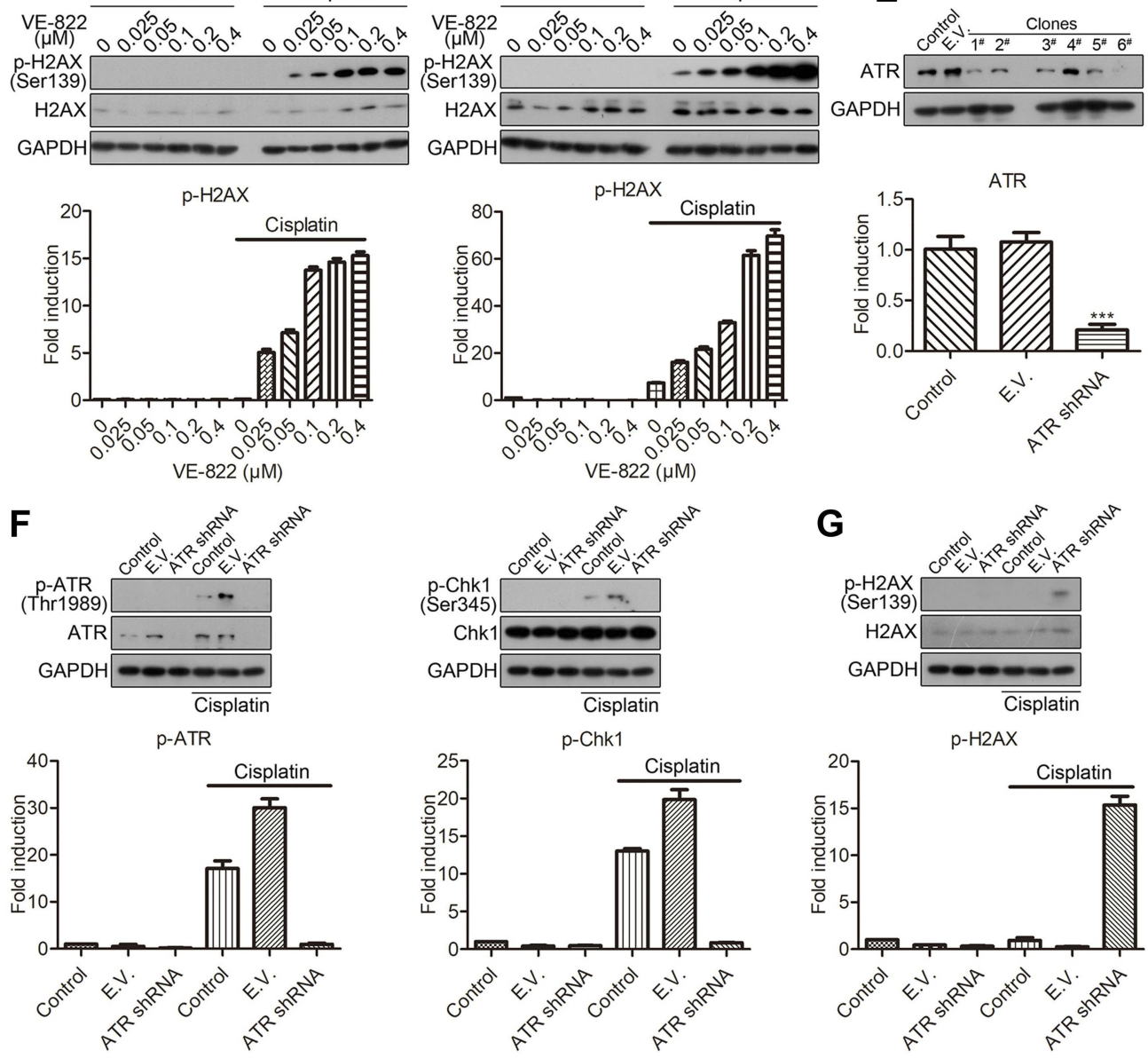

Figure 2 The inhibition of ATR reverses cisplatin-induced DDR. (A) Western blot and semiquantitative analysis of the levels of phosphorylated ATR and ChkI in SWI353 cells treated with the indicated concentrations of VE-822 alone or VE-822 plus $10 \mu \mathrm{M}$ cisplatin for $24 \mathrm{~h}$. (B) Western blot and semiquantitative analysis of the levels of phosphorylated ATR and Chkl in CS-I cells treated with the indicated concentrations of VE-822 alone or VE-822 plus $10 \mu M$ cisplatin for $24 \mathrm{~h}$. (C) Western blot and semiquantitative analysis of the levels of phosphorylated H2AX in SWI353 cells treated with the indicated concentrations of VE-822 alone or VE-822 plus $10 \mu$ M cisplatin for $24 \mathrm{~h}$. (D) Western blot and semiquantitative analysis of the levels of phosphorylated H2AX in CS-I cells treated with the indicated concentrations of VE-822 alone or VE-822 plus $10 \mu \mathrm{M}$ cisplatin for $24 \mathrm{~h}$. (E) Western blot and quantitative RT-PCR analysis of the levels of ATR in SWI353 cells transfected with ATR shRNA. *** P $<0.001$ compared with the control group. (F) Western blot and semiquantitative analysis of the levels of phosphorylated ATR and ChkI in SWI353 cells transfected with ATR shRNA and cultured in the presence or absence of $10 \mu \mathrm{M}$ cisplatin for $24 \mathrm{~h}$. (G) Western blot and semiquantitative analysis of the levels of phosphorylated H2AX in SWI353 cell, transfected with ATR shRNA and cultured in the presence or absence of $10 \mu \mathrm{M}$ cisplatin for $24 \mathrm{~h}$. 
A

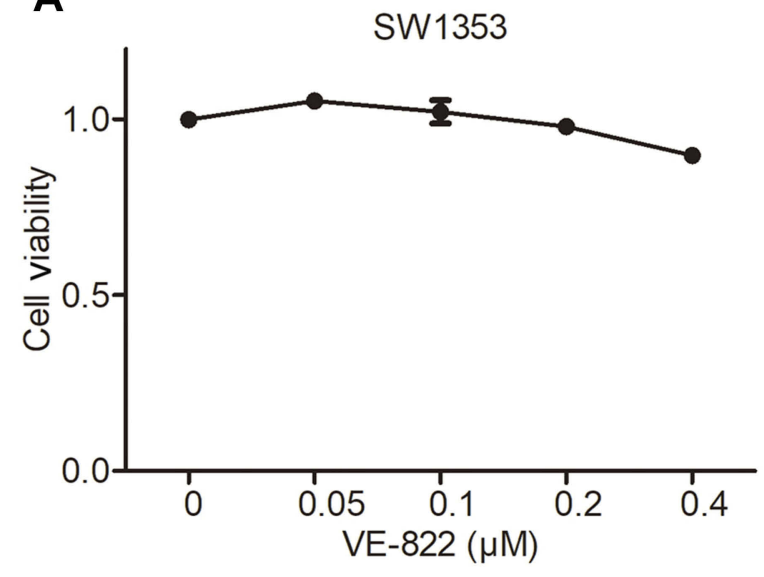

B

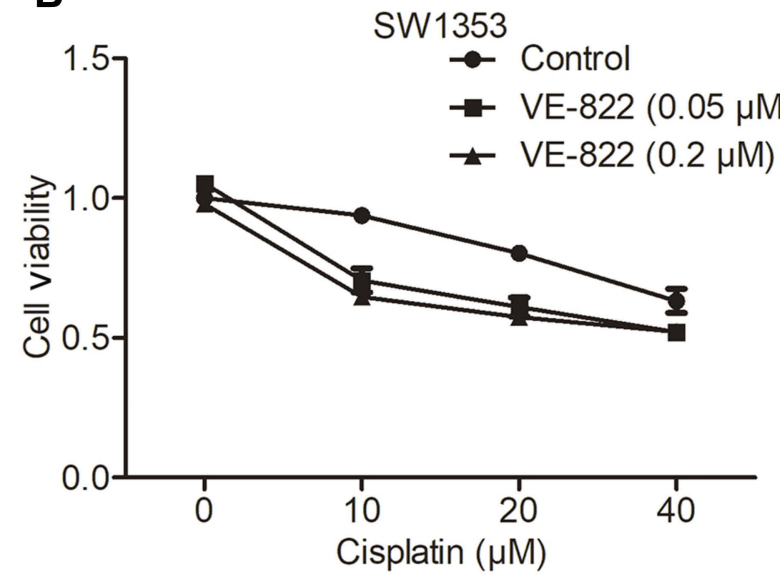

C

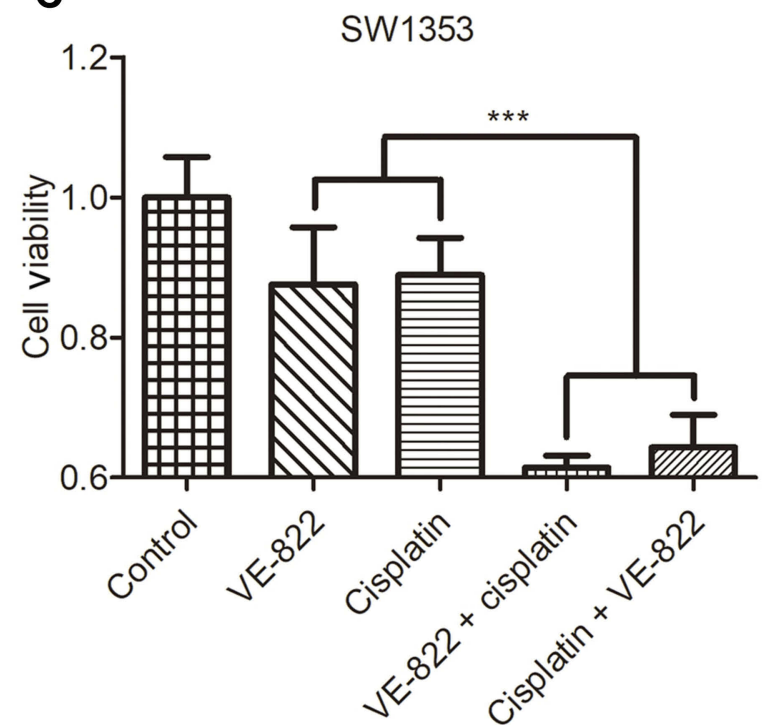

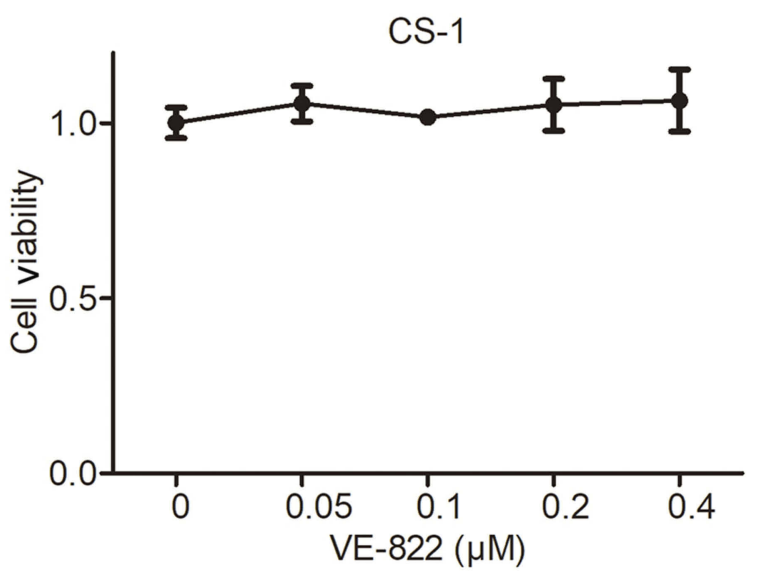

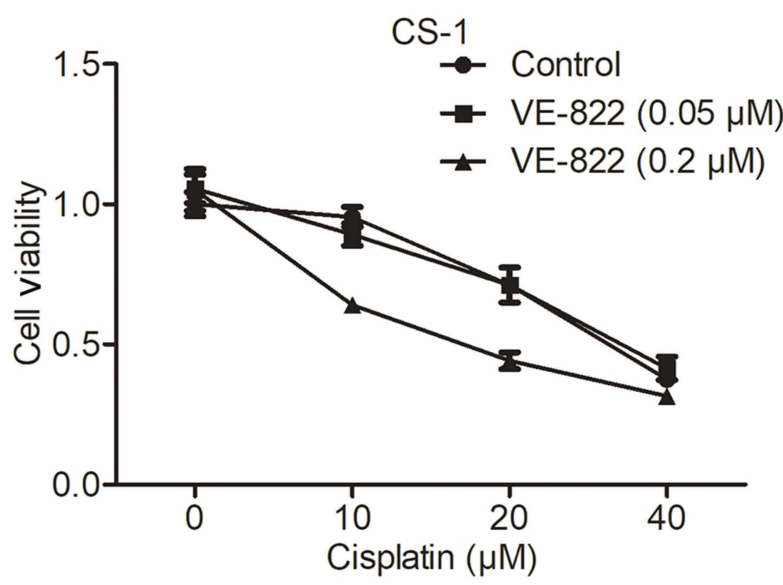

D

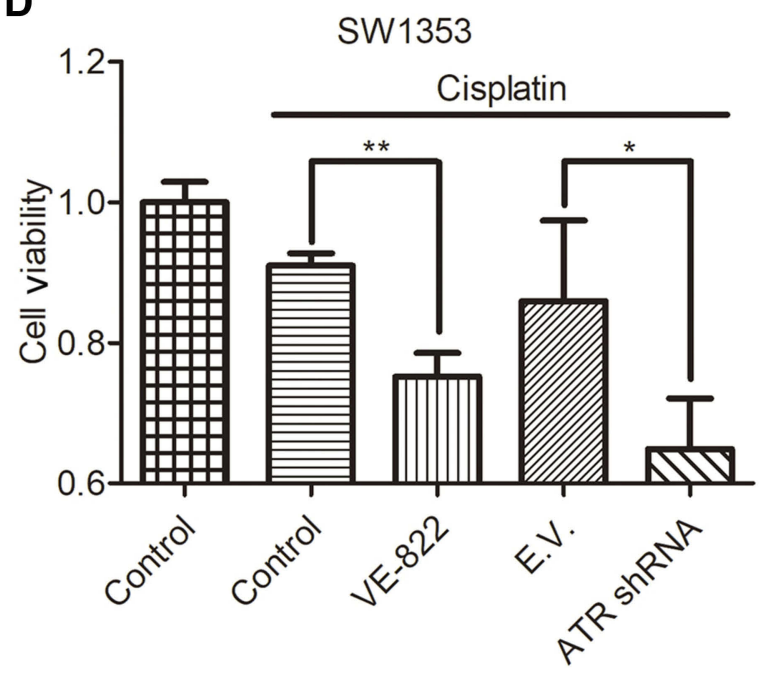

Figure 3 The inhibition of ATR reverses cisplatin-induced inhibition of cell proliferation. (A) CCK-8 analysis of the proliferation of SWI353 and CS-I cells treated with the indicated concentrations of VE-822 for $24 \mathrm{~h}$. (B) CCK-8 analysis of the proliferation of SWI353 and CS-I cells treated with the indicated concentrations of VE-822 and cisplatin for $24 \mathrm{~h}$. (C) CCK-8 analysis of the proliferation of SWI353 cells that were untreated or treated with VE-822 $(0.2 \mu \mathrm{M}, 48 \mathrm{~h})$, cisplatin $(20 \mu \mathrm{M}, 48 \mathrm{~h})$, VE-822 $(0.2 \mu \mathrm{M}, 48 \mathrm{~h})+$ cisplatin $(20 \mu \mathrm{M}, 24 \mathrm{~h})$, or cisplatin $(20 \mu \mathrm{M}, 48 \mathrm{~h})+\mathrm{VE}-822(0.2 \mu \mathrm{M}, 24 \mathrm{~h})$. (D) CCK-8 analysis of the proliferation of SWI353 cells that were untreated or

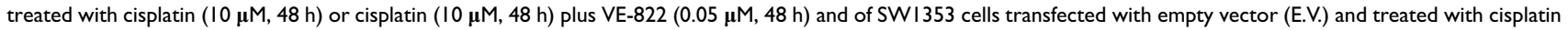
$(10 \mu \mathrm{M}, 48 \mathrm{~h})$ or transfected with ATR shRNA and treated with cisplatin $(10 \mu \mathrm{M}, 48 \mathrm{~h}) . * P<0.05, * * P<0.0 \mathrm{I}, * * * P<0.00 \mathrm{I}$. 
A

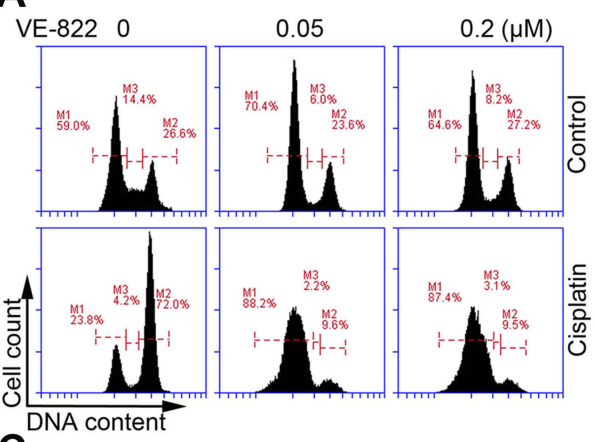

C
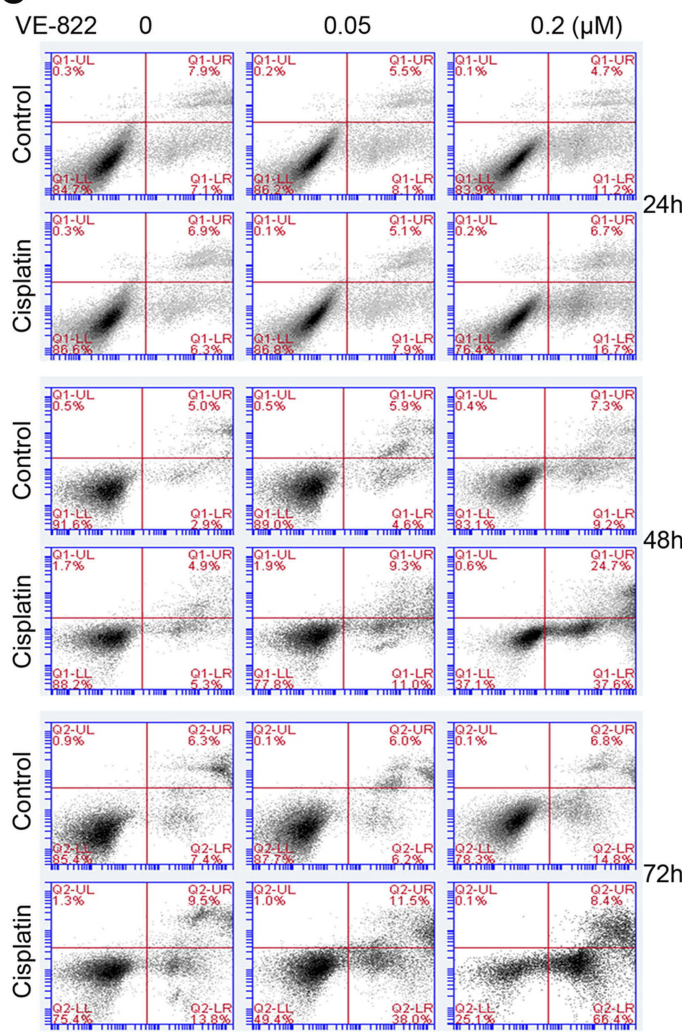

D

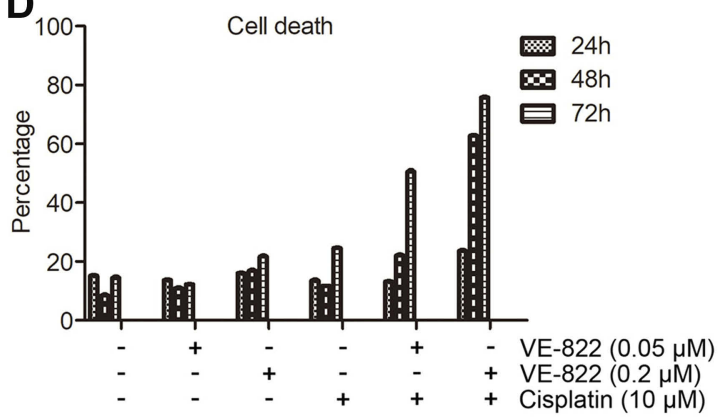

B

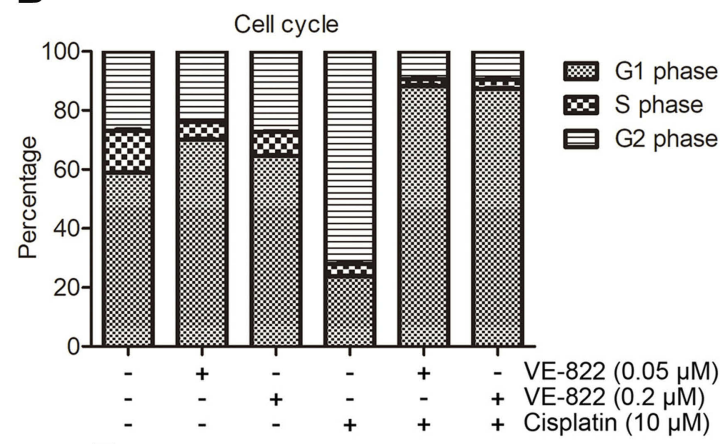

E

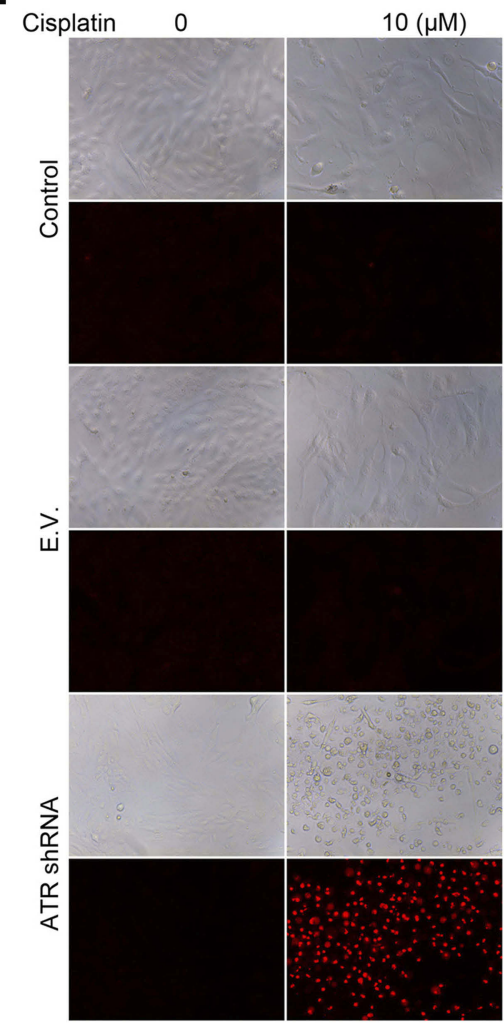

F

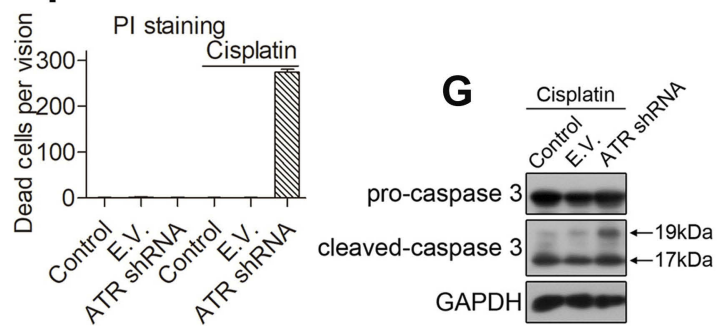

Figure 4 Inhibition of ATR promotes apoptosis induced by cisplatin. (A) PI analysis of cell cycle progression of SWI353 cells treated with the indicated concentrations of VE-822 either alone or in combination with $10 \mu \mathrm{l}$ cisplatin for $24 \mathrm{~h}$. (B) The quantitative data from A. (C) PI/FITC-Annexin V staining analysis of apoptosis of SWI353 cells treated with the indicated concentrations of VE-822 alone or in combination with $10 \mu \mathrm{M}$ cisplatin for 24,48 , or $72 \mathrm{~h}$. (D) The quantitative data from C. (E) PI staining analysis of cell death in SWI353 cells, empty vector (E.V.) transfected SWI353 cells, and ATR shRNA transfected cells that were cultured in the presence or absence of $10 \mu \mathrm{M}$ cisplatin for $24 \mathrm{~h}$. (F) The quantitative data from E. (G) Western blot analysis of the levels of cleaved caspase 3 in untreated SWI353 cells, cells transduced with empty vector (E.V.) or cells transduced with ATR shRNA, treated with $10 \mu \mathrm{M}$ cisplatin for $24 \mathrm{~h}$. 
chondrosarcoma patients, chemotherapy including cisplatin is an additional option. ${ }^{20}$ However, one crucial obstacle encountered often in cisplatin chemotherapy is drug resistance. ${ }^{19}$ Several strategies have been reported to sensitize chondrosarcoma to cisplatin. ${ }^{21-24}$

Cisplatin binds DNA to form intra- and interstrand crosslinks, resulting in DNA double helix disruption and further blockage of DNA replication and transcription. In response to the formation of cisplatin-DNA crosslinks and adducts, DNA damage is induced, which can be sensed by Ataxia telangiectasia mutated (ATM) and Ataxia telangiectasia and Rad-3 related (ATR) kinases, leading to the induction of the DNA damage response. ${ }^{25}$ ATM and ATR phosphorylate downstream kinases, such as checkpoint kinase 1 (Chk1) and checkpoint kinase 2 (Chk2), and regulate multiple cellular responses, including DNA repair, cell cycle arrest, and cell death. ${ }^{25}$ In this study, we found that chondrosarcoma cells at rest did not express phosphorylated ATR or Chk1. However, cisplatin treatment induced the phosphorylation of both ATR and Chk1, suggesting that cisplatin induces the DNA damage response in chondrosarcoma cells.

ATR is activated by DNA damaging agents and regulates cisplatin-induced cell death.

ATR activation facilitates chemotherapy resistance to cisplatin, ${ }^{16,26,27}$ and ATR inhibition enhances cisplatin chemosensitivity. ${ }^{9,28,29}$ In this study, we found that blocking ATR with the inhibitor VE-822 or with ATR shRNA upregulated the phosphorylation of $\mathrm{H} 2 \mathrm{AX}$, a biomarker of DNA damage, ${ }^{30,31}$ indicating that ATR inhibition promoted cisplatin-induced DNA damage. As expected, ATR inhibition promoted cisplatin-induced inhibition of cell proliferation and cell death in chondrosarcoma cells, suggesting that VE-822 mediated inhibition of ATR is a valuable strategy for chemotherapy of chondrosarcoma with cisplatin.

\section{Highlights}

- Cisplatin induces ATR activation in chondrosarcoma cells.

- ATR inhibition reverses the cisplatin-induced DNA damage response and promotes DNA repair.

- Pharmacological and molecular inhibition of ATR signaling sensitizes chondrosarcoma to cisplatin-induced inhibition of cell proliferation.

- Pharmacological and molecular inhibition of ATR signaling sensitizes chondrosarcoma to cisplatin-induced apoptosis.

\section{Acknowledgments}

This study was supported by grants from the Natural Science Foundation of Hunan Province (2018JJ2577) and the Key Research Program of Hunan Province (2018SK2074). We thank Dr. Hui-Min Wang for kindly providing the $5-8 \mathrm{~F}$ cell line, and Dr. Zhenfeng Dua for kindly providing the CS-1 cell line.

\section{Disclosure}

The authors report no conflicts of interest in this work.

\section{References}

1. Dorfman HD, Czerniak B. Bone cancers. Cancer. 1995;75(1 Suppl):203-210. doi:10.1002/1097-0142(19950101)75:1+<203::aidcncr2820751308>3.0.co;2-v

2. Polychronidou G, Karavasilis V, Pollack SM, Huang PH, Lee A, Jones RL. Novel therapeutic approaches in chondrosarcoma. Future Oncol. 2017;13(7):637-648. doi:10.2217/fon-2016-0226

3. Rosenberg AE. WHO classification of soft tissue and bone, fourth edition: summary and commentary. Curr Opin Oncol. 2013;25 (5):571-573. doi:10.1097/01.cco.0000432522.16734.2d

4. Pilie PG, Tang C, Mills GB, Yap TA. State-of-the-art strategies for targeting the DNA damage response in cancer. Nat Rev Clin Oncol. 2019;16(2):81-104. doi:10.1038/s41571-018-0114-z

5. Fokas E, Prevo R, Pollard JR, et al. Targeting ATR in vivo using the novel inhibitor VE-822 results in selective sensitization of pancreatic tumors to radiation. Cell Death Dis. 2012;3:e441. doi:10.1038/cddis.2012.181

6. Surova O, Zhivotovsky B. Various modes of cell death induced by DNA damage. Oncogene. 2013;32(33):3789-3797. doi:10.1038/onc.2012.556

7. Kemp MG, Sancar A. ATR kinase inhibition protects non-cycling cells from the lethal effects of DNA damage and transcription stress. $J$ Biol Chem. 2016;291(17):9330-9342. doi:10.1074/jbc.M116.719740

8. Schmitt A, Knittel G, Welcker D, et al. ATM deficiency is associated with sensitivity to PARP1- and ATR inhibitors in lung adenocarcinoma. Cancer Res. 2017;77(11):3040-3056. doi:10.1158/0008-5472. CAN-16-3398

9. Shi Q, Shen LY, Dong B, et al. The identification of the ATR inhibitor VE-822 as a therapeutic strategy for enhancing cisplatin chemosensitivity in esophageal squamous cell carcinoma. Cancer Lett. 2018;432:56-68. doi:10.1016/j.canlet.2018.06.010

10. Leszczynska KB, Dobrynin G, Leslie RE, et al. Preclinical testing of an Atr inhibitor demonstrates improved response to standard therapies for esophageal cancer. Radiat Oncol. 2016;121(2):232-238. doi:10.1016/j.radonc.2016.10.023

11. Liu P, Shen JK, Hornicek FJ, Liu F, Duan Z. Wnt inhibitory factor 1 (WIF1) methylation and its association with clinical prognosis in patients with chondrosarcoma. Sci Rep. 2017;7(1):1580. doi:10.103 8/s41598-017-01763-8

12. Song Q, Wang G, Chu Y, et al. TNF- $\alpha$ up-regulates cellular inhibitor of apoptosis protein 2 (c-IAP2) via c-Jun N-terminal kinase (JNK) pathway in nasopharyngeal carcinoma. Int Immunopharmacol. 2013;16(2):148-153. doi:10.1016/j.intimp.2013.03.034

13. Song LB, Yan J, Jian SW, et al. Molecular mechanisms of tumorgenesis and metastasis in nasopharyngeal carcinoma cell sublines. $A i$ Zheng. 2002;21(2):158-162.

14. Di Micco R, Sulli G, Dobreva M, et al. Interplay between oncogeneinduced DNA damage response and heterochromatin in senescence and cancer. Nat Cell Biol. 2011;13(3):292-302. doi:10.1038/ncb2170

15. Smith J, Tho LM, Xu N, Gillespie DA. The ATM-Chk2 and ATRChk1 pathways in DNA damage signaling and cancer. Adv Cancer Res. 2010;108:73-112. doi:10.1016/B978-0-12-380888-2.00003-0 
16. Meng Y, Chen CW, Yung MMH, et al. DUOXA1-mediated ROS production promotes cisplatin resistance by activating ATR-Chk1 pathway in ovarian cancer. Cancer Lett. 2018;428:104-116. doi:10.1016/j.canlet.2018.04.029

17. Grossmann KF, Brown JC, Moses RE. Cisplatin DNA cross-links do not inhibit S-phase and cause only a G2/M arrest in Saccharomyces cerevisiae. Mutat Res. 1999;434(1):29-39. doi:10.1016/s0921-8777 (99)00011-7

18. Hsu WH, Zhao X, Zhu J, et al. Checkpoint kinase 1 inhibition enhances cisplatin cytotoxicity and overcomes cisplatin resistance in SCLC by promoting mitotic cell death. J Thorac Oncol. 2019;14:1032-1045. doi:10.1016/j.jtho.2019.01.028

19. Rocha CRR, Silva MM, Quinet A, Cabral-Neto JB, Menck CFM. DNA repair pathways and cisplatin resistance: an intimate relationship. Clinics. 2018;73(suppl 1):e478s. doi:10.6061/clinics

20. Riedel RF, Larrier N, Dodd L, Kirsch D, Martinez S, Brigman BE. The clinical management of chondrosarcoma. Curr Treat Options Oncol. 2009;10(1-2):94-106. doi:10.1007/s11864-009-0088-2

21. Zhu Z, Wang CP, Zhang YF, Nie L. MicroRNA-100 resensitizes resistant chondrosarcoma cells to cisplatin through direct targeting of mTOR. Asian Pac J Cancer Prev. 2014;15(2):917-923. doi:10.7314/apjcp.2014.15.2.917

22. Song YD, Zhang KF, Liu D, et al. Inhibition of EGFR-induced glucose metabolism sensitizes chondrosarcoma cells to cisplatin. Tumour Biol. 2014;35(7):7017-7024. doi:10.1007/s13277-014-1902-4

23. Huang K, Chen J, Yang MS, Tang YJ, Pan F. Inhibition of Src by microRNA-23b increases the cisplatin sensitivity of chondrosarcoma cells. Cancer Biomark. 2017;18(3):231-239. doi:10.3233/CBM-160102
24. Chen C, Zhou H, Xu L, et al. Recombinant human PDCD5 sensitizes chondrosarcomas to cisplatin chemotherapy in vitro and in vivo. Apoptosis. 2010;15(7):805-813. doi:10.1007/s10495-010-0489-5

25. Zhu S, Pabla N, Tang C, He L, Dong Z. DNA damage response in cisplatin-induced nephrotoxicity. Arch Toxicol. 2015;89(12):21972205. doi:10.1007/s00204-015-1633-3

26. Zhang B, Cui B, Du J, et al. ATR activated by EB virus facilitates chemotherapy resistance to cisplatin or 5-fluorouracil in human nasopharyngeal carcinoma. Cancer Manag Res. 2019;11:573-585. doi:10.2147/CMAR.S187099

27. Chen S, Chen X, Xie G, et al. Cdc6 contributes to cisplatin-resistance by activation of ATR-Chk1 pathway in bladder cancer cells. Oncotarget. 2016;7(26):40362-40376. doi:10.18632/oncotarget.9616

28. Li XQ, Ren J, Chen P, et al. Co-inhibition of Pol eta and ATR sensitizes cisplatin-resistant non-small cell lung cancer cells to cisplatin by impeding DNA damage repair. Acta Pharmacol Sin. 2018;39(8):1359-1372. doi:10.1038/aps.2017.187

29. Jiang HG, Chen P, Su JY, et al. Knockdown of REV3 synergizes with ATR inhibition to promote apoptosis induced by cisplatin in lung cancer cells. J Cell Physiol. 2017;232(12):3433-3443. doi:10.1002/ jcp. 25792

30. Rao VA, Agama K, Holbeck S, Pommier Y. Batracylin (NSC 320846), a dual inhibitor of DNA topoisomerases I and II induces histone gamma-H2AX as a biomarker of DNA damage. Cancer Res. 2007;67(20):9971-9979. doi:10.1158/0008-5472.CAN-07-0804

31. Alipoor A, Fardid R, Sharifzadeh S. Evaluating gamma-H2AX expression as a biomarker of DNA damage after X-ray in angiography patients. J Biomed Phys Eng. 2018;8(4):393-402.

\section{Publish your work in this journal}

OncoTargets and Therapy is an international, peer-reviewed, open access journal focusing on the pathological basis of all cancers, potential targets for therapy and treatment protocols employed to improve the management of cancer patients. The journal also focuses on the impact of management programs and new therapeutic agents and protocols on patient perspectives such as quality of life, adherence and satisfaction. The manuscript management system is completely online and includes a very quick and fair peer-review system, which is all easy to use. Visit http://www.dovepress.com/ testimonials.php to read real quotes from published authors. 